\title{
The impact of channel fin width on electrical characteristics of Si-FinFET
}

\author{
Yousif Atalla $^{1}$, Yasir Hashim ${ }^{2}$, Abdul Nasir Abd Ghafar ${ }^{1}$ \\ ${ }^{1}$ Faculty of Electrical and Electronics Engineering Technology, University Malaysia Pahang (UMP), Pahang, Malaysia \\ ${ }^{2}$ Department of Computer Engineering, Faculty of Engineering, Tishk International University (TIU), Kurdistan-Erbil, Iraq
}

\begin{tabular}{l} 
Article Info \\
\hline Article history: \\
Received Sep 3, 2020 \\
Revised Jul 23, 2021 \\
Accepted Aug 11, 20 \\
\hline Keywords: \\
Channel fin width \\
FinFET \\
MOSFET \\
Subthreshold swing \\
Temperature
\end{tabular}

\begin{abstract}
This paper studies the impact of fin width of channel on temperature and electrical characteristics of fin field-effect transistor (FinFET). The simulation tool multi-gate field effect transistor (MuGFET) has been used to examine the FinFET characteristics. Transfer characteristics with various temperatures and channel fin width $\left(\mathrm{W}_{\mathrm{F}}=5,10,20,40\right.$, and $\left.80 \mathrm{~nm}\right)$ are at first simulated in this study. The results show that the increasing of environmental temperature tends to increase threshold voltage, while the subthreshold swing (SS) and drain-induced barrier lowering (DIBL) rise with rising working temperature. Also, the threshold voltage decreases with increasing channel fin width of transistor, while the SS and DIBL increase with increasing channel fin width of transistor, at minimum channel fin width, the SS is very near to the best and ideal then its value grows and going far from the ideal value with increasing channel fin width. So, according to these conditions, the minimum value as possible of fin width is the preferable one for FinFET with better electrical characteristics.
\end{abstract}

This is an open access article under the CC BY-SA license.

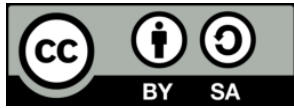

\section{Corresponding Author:}

Yasir Hashim

Department of Computer Engineering, Tishk International University (TIU)

Kurdistan-Erbil, Iraq

Email: yasir.hashim@tiu.edu.iq; yasir.hashim@ieee.org

\section{INTRODUCTION}

The scaling down of conventional metal oxide semiconductor field effect transistor (MOSFET) has become harder because it has serious effects of short channel on the characteristics of transistor when it is minimized lower than $32 \mathrm{~nm}$ [1], the minimization width and length of channel of MOSFET guide to a bad characteristics and increasing average consumed power. The main reason of these bad performances is related to the implementing the MOSFET inside the Si wafer, so, the main idea to improve the performances of transistor is free the MOSFET and isolate its structure on the surface of Si wafer. Much silicon on insulator silicon on insulator (SOI) structure have been invented to isolate transistor from silicon bulk like silicon nanowire transistor, carbon nanotube transistor, fin field-effect transistor (FinFET) structure. One of those new innovated structures is the FinFET as shown in Figure 1 [2]. The FinFET structure has free from many serious defies related with the continual scaling down structure of planer MOSFET [3]-[5].

The first FinFET like structure has been fabricated by Hashimoto et al. [6], the research of Hashimoto et al. reports a new double-gate SOI structure MOSFET structure [6]. In the last decade, many researchers direct their attention to the FinFET because of good performances in Nano-dimensional range and to overcome the short channel effect problems of conventional planar MOSFET [7]-[11]. The excellent short-channel behavior of FinFET results increase attention from semiconductor industries as well as the researchers [12]. 
The sensor for subsumed electronic applications is the sensor of temperature based on semiconductor devices [13]. Temperature sensors based on MOSFET could be designed on the fundamental of the effect of working temperature on the I-V characteristics of the MOSFET [14]-[15]. While the bipolar junction transistor possible to use as a sensor of temperature by use it as a diode by connecting its base and collector together. In a similar way, a MOSFET could be used in diode mode by connecting the drain or source with gate to use it as a temperature sensor Figure 2.

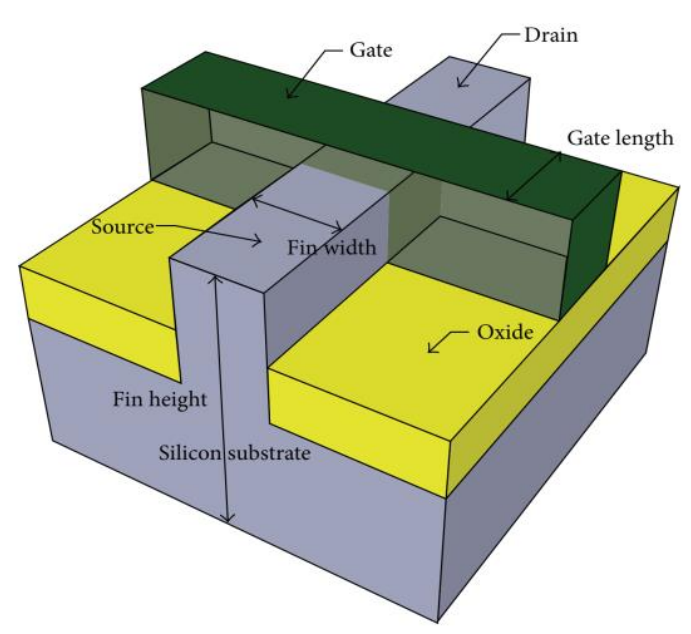

Figure 1. FinFET structure [2]

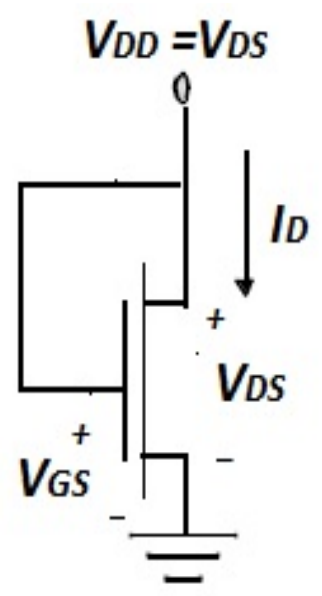

Figure 2. Diode mode of MOSFET to use it as a sensor of temperature $\left(\mathrm{V}_{\mathrm{g}}=\mathrm{V}_{\mathrm{d}}=\mathrm{V}_{\mathrm{DD}}\right)$

The Nano-dimensional electronic devices such as diodes, transistors, capacitors, and resistors, have newly become marketable in the industry of electronics because of their so tiny applicable circuits. The characteristics of these Nano devices, which may correspond to enormous novel applications [16]-[20], will likely build on the Nano-dimensional feature of such devices. The new versions of chips with these comparatively novel and Nano-dimensional transistors may be further considered when new future research findings are achieved. Also, the new designs and structures of MOSFET with Nano-dimensions are included in novel technologies and consequently require more investigation and improvements to overcome the limitations of normal MOSFET structure when its dimensions going down to Nano range.

Simulation of nano-devices in nano-electronic has extra importance in understanding those new nano-devices' merits. So, simulation tools are used in this research for realization and valuation of the FinFET sensitivity with temperature. The simulation tools have an ability to support the research fields for more characterization the Nano-dimensional devices [21]. As well, simulation tools can define the nanodevice failure, in addition, retrenchment the costs of fabrication of these nano-devices in the Nano dimensions field [22], [23].

\section{RESEARCH METHOD}

In this study, multi-gate field effect transistor (MuGFET) is used as the simulation tool to explore the fin field-effect transistor (FinFET) characteristics. The $I_{d}-V_{g}$ characteristics of FinFET under different environmental situations and with different parameters are examined. The impact of fin width of the gate on the characteristics of temperature has been studied depending on the output characteristics of the FinFET. The simulation tool MuGFET [24] has been used in this research.

MuGFET simulator depends mainly on PADRE or PROPHET for simulation, PADRE or PROPHET was invented at Bell Laboratories. The partial differential equation profiler for one, two, or three dimension were used in the PROPHET, and PADRE simulation depends on a device-oriented for 3D or 2D transistors structure with arbitrary geometry [24]. This simulation tool has an ability to provide adequate characteristic curves of FinFET for researcher to aid him completely explain and understand the FinFET physics. Furthermore, the simulation tool gives self-consistent solutions to drift-diffusion and Poisson equations [25], also this simulation tool, when calculating FinFET characteristics, can be used to simulate the movement of transport objects. In this research, the output characteristics $\left(I_{d}-V_{g}\right)$ of FinFET at temperature range from $250 \mathrm{~K}^{\circ}$ to $400 \mathrm{~K}^{\circ}$ with steps $25 \mathrm{~K}^{\circ}$ are explored as shown in Figures 3-8 with parameters in Table 1. 
Table 1. The simulated FinFET dimensions and parameters of used in this study

\begin{tabular}{cc}
\hline Parameter & Values \\
\hline Length of channel $\left(\mathrm{L}_{\mathrm{g}}\right)$ & $85 \mathrm{~nm}$ \\
Length of source $\left(\mathrm{L}_{\mathrm{s}}\right)$ & $50 \mathrm{~nm}$ \\
Length of drain $\left(\mathrm{L}_{\mathrm{d}}\right)$ & $50 \mathrm{~nm}$ \\
concentration of channel (P-type) & $10^{16} \mathrm{~cm}^{-3}$ \\
concentration of source $(\mathrm{N}$-type $)$ & $10^{19} \mathrm{~cm}^{-3}$ \\
concentration of drain $(\mathrm{N}-$ type $)$ & $10^{19} \mathrm{~cm}^{-3}$ \\
Thickness of oxide $\left(\mathrm{T}_{\mathrm{ox}}\right)$ & $2.5 \mathrm{~nm}$ \\
Fin width of gate $\left(\mathrm{W}_{\mathrm{F}}\right)$ & $5,10,20,40$, and $80 \mathrm{~nm}$ \\
\hline
\end{tabular}

\section{RESULTS AND DISCUSSION}

Figure 3 shows the effect of working temperature on the FinFET important parameters including drain-induced barrier lowering (DIBL), subthreshold swing (SS), and threshold voltage $\left(\mathrm{V}_{\mathrm{T}}\right)$ at fin width $\mathrm{W}_{\mathrm{F}}=5 \mathrm{~nm}$, all measurements done with working temperature range from 250 to $400 \mathrm{~K}^{\circ}$. It is clear that the increasing working temperature tends to decrease $V_{T}$ linearly, at $250 \mathrm{~K}^{\circ}$ the $\mathrm{V}_{\mathrm{T}}=0.65 \mathrm{~V}$ which the higher value and at $400 \mathrm{~K}^{\circ}$ the $\mathrm{V}_{\mathrm{T}}=0.62 \mathrm{~V}$ which is the lower. The slope of curve which represents the threshold voltage sensitivity with working temperature of transistor is $-0.16 \mathrm{mV} / \mathrm{K}^{\circ}$. While, the best $\mathrm{SS}$ (at $49.7 \mathrm{mV} / \mathrm{dec})$ and the near value to ideal SS $(49.6 \mathrm{mV} / \mathrm{dec})$ happen at lower temperature at $250 \mathrm{~K}^{\circ}$ and then increases linearly with increasing temperature until reaching $(80.09 \mathrm{mV} / \mathrm{dec})$ at $400 \mathrm{~K}^{\circ}$, which is also near to the ideal SS at $79.4 \mathrm{mV} / \mathrm{dec}$ at $400 \mathrm{~K}^{\circ}$, so for all the range of T the SS is very close to the ideal values. The SS sensitivity to the working temperature is $0.196 \mathrm{mV} / \mathrm{dec} . \mathrm{K}^{\circ}$. DIBL increases linearly with increasing working temperature, the minimum value is $26.9 \mathrm{mV} / \mathrm{V}$ and the maximum is $79.4 \mathrm{mV} / \mathrm{V}$.

Figure 4 presents the impact of working temperature at $\mathrm{W}_{\mathrm{F}}=10 \mathrm{~nm}$ on the DIBL, SS, and $\mathrm{V}_{\mathrm{T}}$ of FinFET, the working temperature $\mathrm{T}$ range from $250 \mathrm{~K}^{\circ}$ to $400 \mathrm{~K}^{\circ}$. This figure illustrates that the increasing working temperature results decreasing $\mathrm{V}_{\mathrm{T}}$ linearly, the $\mathrm{V}_{\mathrm{T}}$ decreases linearly from $0.59 \mathrm{~V}$ at $250 \mathrm{~K}^{\circ}$ to $0.55 \mathrm{~V}$ at $400 \mathrm{~K}^{\circ}$. The slope of curve which represents the threshold voltage sensitivity with working temperature of transistor is $-0.31 \mathrm{mV} / \mathrm{K}^{\circ}$. While, at $250 \mathrm{~K}$ working temperature the $\mathrm{SS}$ value is $49.6 \mathrm{mV} / \mathrm{dec}$ which represent the nearest value to the ideal SS at $49.6 \mathrm{mV} / \mathrm{dec}$ at $250 \mathrm{~K}^{\circ}$, and then with increasing working temperature up to $400 \mathrm{~K}$ the SS increased up to $80.99 \mathrm{mV} / \mathrm{dec}$, this SS represents the farthest value from the ideal SS at $79.4 \mathrm{mV} / \mathrm{dec}$ at $400 \mathrm{~K}^{\circ}$. Also, the SS here is very close to the ideal values with all range of T. The SS sensitivity to the working temperature is $0.21 \mathrm{mV} / \mathrm{dec} . \mathrm{K}^{\circ}$. The DIBL increases as working temperature increased but at lower values than $\mathrm{W}_{\mathrm{F}}=5 \mathrm{~nm}$.

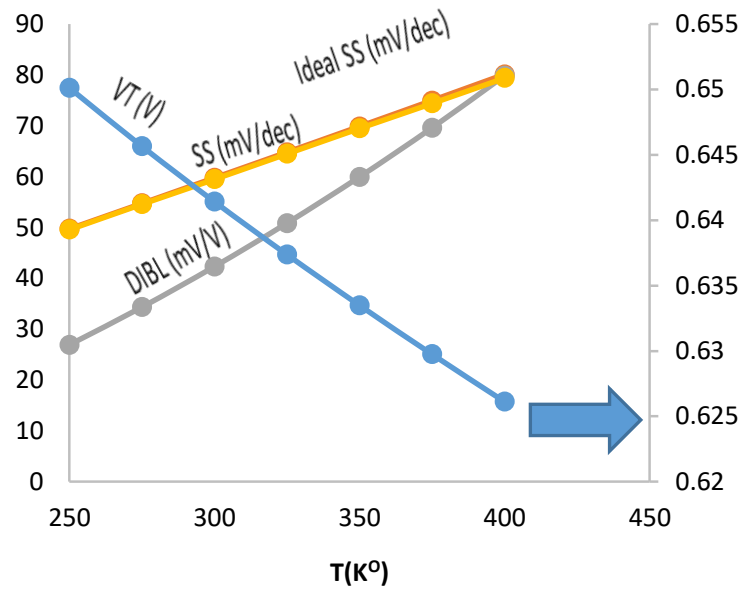

Figure 3. Temperature characteristics of $\mathrm{V}_{\mathrm{T}}, \mathrm{SS}$ and DIBL of the FinFET at $\mathrm{W}_{\mathrm{F}}=5 \mathrm{~nm}$

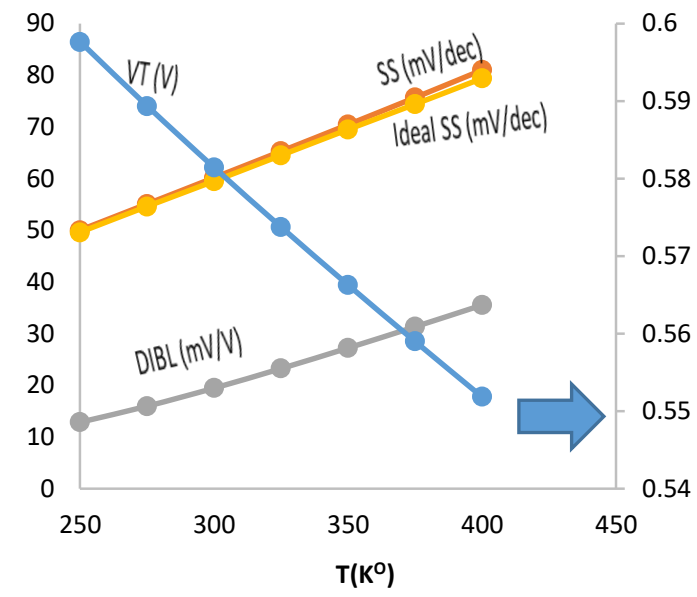

Figure 4. Temperature characteristics of $\mathrm{V}_{\mathrm{T}}, \mathrm{SS}$ and DIBL of the FinFET at $\mathrm{W}_{\mathrm{F}}=10 \mathrm{~nm}$

Figure 5 presents the impact of working temperature on the FinFET important parameters including $\mathrm{V}_{\mathrm{T}}$, DIBL and SS at fin width $\mathrm{W}_{\mathrm{F}}=20 \mathrm{~nm}$, all measurements done with working temperature range from 250 up to $400 \mathrm{~K}^{\circ}$. It is clear that $\mathrm{V}_{\mathrm{T}}$ decreasing linearly with increasing working temperature, at $250 \mathrm{~K}^{\circ}$ the $\mathrm{V}_{\mathrm{T}}=0.54 \mathrm{~V}$ which the higher value and at $400 \mathrm{~K}^{\circ}$ the $\mathrm{V}_{\mathrm{T}}=0.49 \mathrm{~V}$ which is the lower. The slope of curve which represents the threshold voltage sensitivity with working temperature of transistor is $-0.44 \mathrm{mV} / \mathrm{K}^{\circ}$. While, the best SS (at $51.7 \mathrm{mV} / \mathrm{dec}$ ) and the near value to ideal SS $(49.6 \mathrm{mV} / \mathrm{dec}$ ) happen at lower 
temperature at $250 \mathrm{~K}^{\circ}$ and then increases linearly with increasing temperature until reaching $(84.93 \mathrm{mV} / \mathrm{dec})$ at $400 \mathrm{~K}^{\circ}$, which is far from ideal SS at $79.4 \mathrm{mV} / \mathrm{dec}$ at $400 \mathrm{~K}^{\circ}$, so at lower $\mathrm{T}$ the $\mathrm{SS}$ is very close to the ideal values. The SS sensitivity to the working temperature is $0.22 \mathrm{mV} / \mathrm{dec} . \mathrm{K}^{\circ}$. DIBL increases linearly with increasing working temperature until $350 \mathrm{~K}^{\circ}$ then decreases with increasing working temperature.

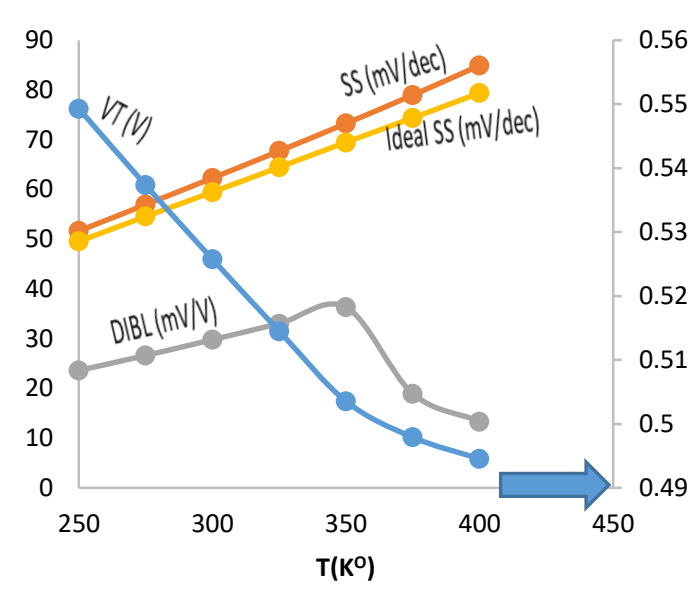

Figure 5. Temperature characteristics of $\mathrm{V}_{\mathrm{T}}, \mathrm{SS}$ and DIBL of the FinFET at $\mathrm{W}_{\mathrm{F}}=20 \mathrm{~nm}$

Figure 6 presents the impact of working temperature at $\mathrm{W}_{\mathrm{F}}=40 \mathrm{~nm}$ on the DIBL, SS, and $\mathrm{V}_{\mathrm{T}}$ of FinFET, the working temperature T range from $250 \mathrm{~K}^{\circ}$ to $400 \mathrm{~K}^{\circ}$. This figure illustrates that the increasing of working temperature results decreasing $\mathrm{V}_{\mathrm{T}}$ linearly, the $\mathrm{V}_{\mathrm{T}}$ decreases linearly from 0.49 at $250 \mathrm{~K}^{\circ}$ to $0.45 \mathrm{~V}$ at $400 \mathrm{~K}^{\circ}$. The slope of curve which represents the threshold voltage sensitivity with working temperature of transistor is $-0.47 \mathrm{mV} / \mathrm{K}^{\circ}$. While, at $\mathrm{T}=250 \mathrm{~K}^{\circ}$ the $\mathrm{SS}$ is at $61.99 \mathrm{mV} / \mathrm{dec}$, this value is the nearest to the ideal SS at $49.6 \mathrm{mV} / \mathrm{dec}$ and then working temperature increases the $\mathrm{SS}$ increased up to $106.49 \mathrm{mV} / \mathrm{dec}$ at $400 \mathrm{~K}^{\circ}$, this $\mathrm{SS}$ value is the farthest value from the ideal $\mathrm{SS}$ at $79.4 \mathrm{mV} / \mathrm{dec}$ at $400 \mathrm{~K}^{\circ}$. Also, all values of SS here is very far from the ideal values with all range of T. The SS sensitivity to the working temperature is $0.27 \mathrm{mV} / \mathrm{dec} . \mathrm{K}$. The DIBL increases as working temperature increasing, DIBL increases from 26.54 up to $52.07 \mathrm{mV} / \mathrm{V}$ with the same range of $\mathrm{T}$.

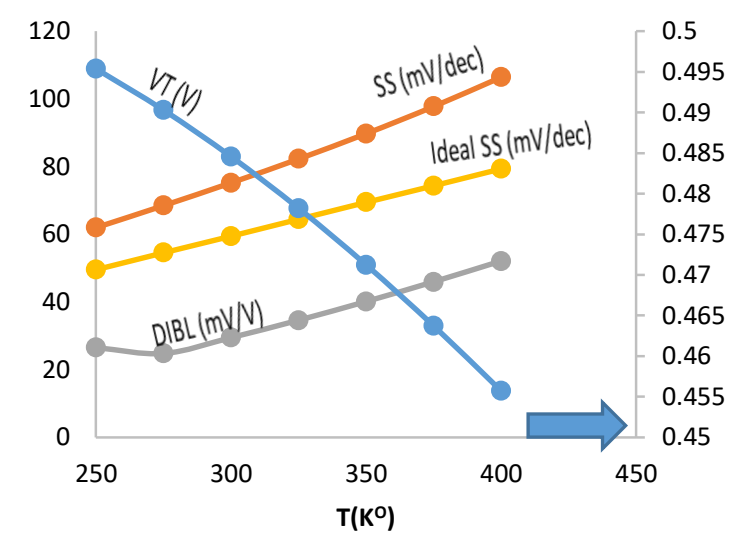

Figure 6. Temperature characteristics of $\mathrm{V}_{\mathrm{T}}, \mathrm{SS}$ and DIBL of the FinFET at $\mathrm{W}_{\mathrm{F}}=40 \mathrm{~nm}$

Figure 7 shows the effect of increasing working temperature from $250 \mathrm{~K}^{\circ}$ to $400 \mathrm{~K}^{\circ}$ on $\mathrm{V}_{\mathrm{T}}, \mathrm{SS}$ and DIBL at $\mathrm{W}_{\mathrm{F}}=80 \mathrm{~nm}$. It is clear that with increasing working temperature the values of $\mathrm{V}_{\mathrm{T}}$ decreases. The slope of curve which represents the threshold voltage sensitivity with working temperature of transistor is $-0.6 \mathrm{mV} / \mathrm{K}^{\circ}$. While SS and DIBL increased with increasing working temperature. This figure illustrates that for the range of temperature the values of change of the $\mathrm{V}_{\mathrm{T}}$ from 0.38 to $0.29 \mathrm{~V}$, SS from 130.66 to 
$253.20 \mathrm{mV} / \mathrm{dec}$ and DIBL from 230.37 to $295.89 \mathrm{mV} / \mathrm{V}$, respectively. SS values increases with increasing temperature while the nearest value to the ideal happens at lower temperature. The SS sensitivity to the working temperature is $0.8 \mathrm{mV} / \mathrm{dec} . \mathrm{K}$.

Figure 8 shows the effect of fin width of FinFET on the $\mathrm{V}_{\mathrm{T}}, \mathrm{SS}$, and DIBL, the FinFET channel width from $5-80 \mathrm{~nm}$ at $20 \mathrm{~nm}$ steps at working temperature $\mathrm{T}=300 \mathrm{~K}^{\circ}$. When the width of the channel increased, it is notice that there is a decrease in $\mathrm{V}_{\mathrm{T}}$ and it is also notice an increase in DIBL with the $\mathrm{W}_{\mathrm{F}}$ greater than $40 \mathrm{~nm}$, the $S S$ increases with increasing $W_{F}$, when the $W_{F}$ increases from $5 \mathrm{~nm}$, to $20 \mathrm{~nm}$, the SS approaches the very ideal value and when the $\mathrm{W}_{\mathrm{F}}$ increases more than $20 \mathrm{~nm}$, the $\mathrm{SS}$ increased away the ideal value as shown in Figure 8. So, this research shows the best range for $\mathrm{W}_{\mathrm{F}}$ is 5 to $20 \mathrm{~nm}$. Figure 9 illustrates the temperature sensitivity of $\mathrm{V}_{\mathrm{T}}\left(\Delta \mathrm{V}_{\mathrm{T}} / \Delta \mathrm{T}\right)$ and $\mathrm{SS}(\mathrm{SS} / \Delta \mathrm{T})$ with FinFET channel fin width $\left(\mathrm{W}_{\mathrm{F}}\right)$. According to this figure, the lower sensitivity for both threshold voltage and subthreshold swing with better stability with working temperature happen at lower $\mathrm{W}_{\mathrm{F}}$.

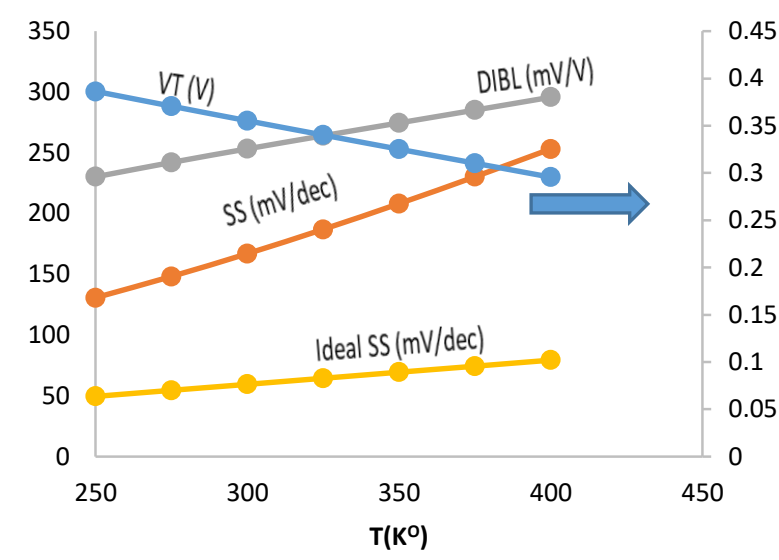

Figure 7. Temperature characteristics of $\mathrm{V}_{\mathrm{T}}, \mathrm{SS}$ and DIBL of the FinFET at $\mathrm{W}_{\mathrm{F}}=80 \mathrm{~nm}$

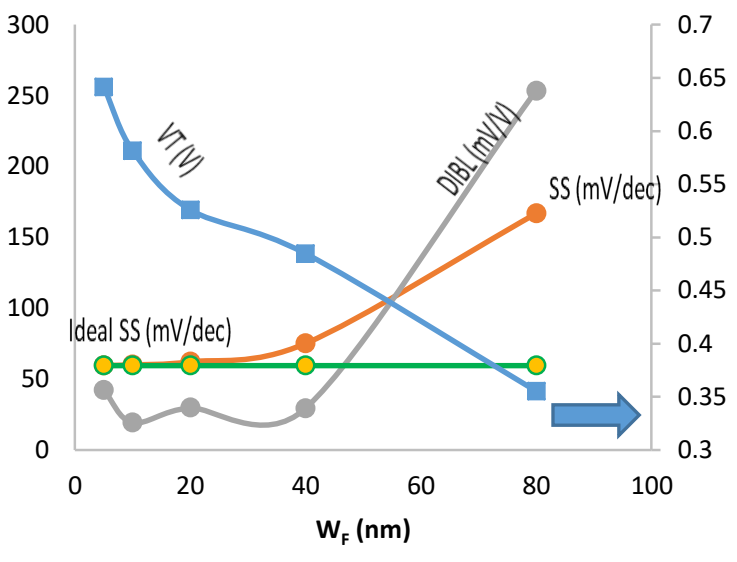

Figure 8 . The $\mathrm{V}_{\mathrm{T}}$, SS, and DIBL with the increase of the FinFET channel fin width $\left(\mathrm{W}_{\mathrm{F}}\right)$

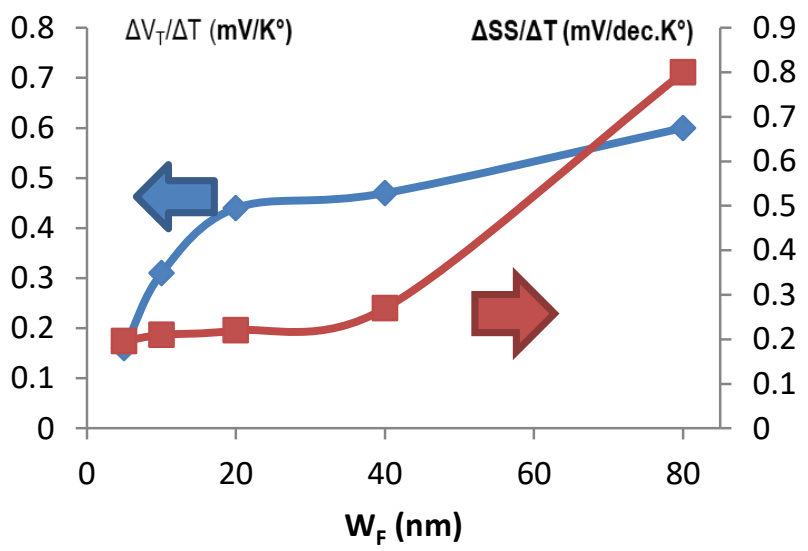

Figure 9. The temperature sensitivity of $\mathrm{V}_{\mathrm{T}}$ and $\mathrm{SS}$, with FinFET channel fin width $\left(\mathrm{W}_{\mathrm{F}}\right)$

\section{CONCLUSION}

The impact of environmental temperatures with range of 250 to $400 \mathrm{~K}^{\circ}$ on the FinFET electrical parameters has been studied different channel fin widths $\left(\mathrm{W}_{\mathrm{F}}=5,10,20,40\right.$, and $\left.80 \mathrm{~nm}\right)$. The results show that the $\mathrm{V}_{\mathrm{T}}$ lowering with rising working temperature, while the increasing of working temperature tends to increase SS and DIBL. Also, the threshold voltage decreases with increasing channel fin width of transistor, while SS and DIBL increase with increasing channel fin width of transistor. The (SS is very near to the ideal value at $5 \mathrm{~nm}$ channel fin width then diverges and increases with increasing channel fin width. So, based on the $\mathrm{SS}$ and $\mathrm{V}_{\mathrm{T}}$ temperature sensitivity, the FinFET with lower channel fin width is the best for stability with the temperatures range of 250 to $400 \mathrm{~K}^{\circ}$. 


\section{ACKNOWLEDGEMENTS}

The authors would like to thank Tishk International University (TIU), the Ministry of Higher Education (in Malaysia) for providing financial support under Fundamental research grant No. FRGS/1/2019/TK04/UMP/02/15 (University reference RDU1901199) and Universiti Malaysia Pahang (UMP) for laboratory facilities as well as additional financial support under Internal Research grant RDU1901199.

\section{REFERENCES}

[1] S. Zhang, "Review of modern field effect transistor technologies for scaling," Journal of Physics: Conference Series, vol. 1617, 2020, Art. no. 012054, doi:10.1088/1742-6596/1617/1/012054.

[2] H. C. Chin, C. S. Lim, and M. L. P. Tan, " Design and performance analysis of 1-Bit FinFET full adder cells for subthreshold region at $16 \mathrm{~nm}$ process technology," Journal of Nanomaterials, vol. 16, no. 1, pp. 1-13, 2015, Art. no. 175, doi: $10.1155 / 2015 / 726175$.

[3] S. Sarkhel, P. Saha, and S. K. Sarkar, "Exploring the threshold voltage characteristics and short channel behavior of gate engineered front gate stack MOSFET with graded channel," Silicon, vol. 11, no. 3, pp. 1421-1428, 2019, doi: 10.1007/s12633018-9950-9.

[4] A. Gill, C. Madhu and P. Kaur, "Investigation of short channel effects in bulk MOSFET and SOI FinFET at 20 nm node technology," Annual IEEE India Conference (INDICON), New Delhi, 2015, pp. 1-4, doi: 10.1109/INDICON.2015.7443263.

[5] P. Saha, P. Banerjee, D. K. Dash and S. K. Sarkar, "Impact of trapped interface charges on short channel characteristics of WFE high-K SOI MOSFET," Devices for Integrated Circuit (DevIC), Kalyani, India, pp. 118-123, 2019, doi: 10.1109/DEVIC.2019.8783522.

[6] D. Hisamoto, T. Kaga, Y. Kawamoto, and E. Takeda, "A fully depleted lean-channel transistor (DELTA)-a novel vertical ultrathin SOI MOSFET," Proceedings of the International Electron Devices Meeting (IEDM '89), 1989, pp. 833-836, doi: 10.1109/IEDM.1989.74182.

[7] D. Hisamoto et al., "FinFET-a self-aligned double-gate MOSFET scalable to $20 \mathrm{~nm}$," in IEEE Transactions on Electron Devices, vol. 47, no. 12, pp. 2320-2325, Dec. 2000, doi: 10.1109/16.887014.

[8] E. Yu, K. Heo and S. Cho, "Characterization and optimization of inverted-T FinFET under nanoscale dimensions," IEEE Transactions on Electron Devices, vol. 65, no. 8, pp. 3521-3527, Aug. 2018, doi: 10.1109/TED.2018.2846478.

[9] J. Singh et al., "14-nm FinFET technology for analog and RF applications," IEEE Transactions on Electron Devices, vol. 65, no. 1, pp. 31-37, Jan. 2018, doi: 10.1109/TED.2017.2776838.

[10] Y. Zhang and T. Palacios, "(ultra) wide-bandgap vertical power FinFETs," IEEE Transactions on Electron Devices, vol. 67, no. 10, pp. 3960-3971, Oct. 2020, doi: 10.1109/TED.2020.3002880.

[11] J. Pruefer et al., "Compact modeling of short-channel effects in staggered organic thin-film transistors," in IEEE Transactions on Electron Devices, vol. 67, no. 11, pp. 5082-5090, Nov. 2020, doi: 10.1109/TED.2020.3021368.

[12] D. Bhattacharya and N. K. Jha, "FinFETs: from devices to architectures," Advances in Electronics, vol. 2014, pp. 1-21, 2014, doi: $10.1155 / 2014 / 365689$.

[13] G. Meijer, G. Wang, and F. Fruett, "Temperature sensors and voltage references implemented in CMOS technology," IEEE Sensors Journal, vol. 1, no. 3, pp. 225-234, Oct. 2001, doi: 10.1109/JSEN.2001.954835.

[14] N. Tega, S. Sato, and A. Shima, "Comparison of extremely high-temperature characteristics of planar and three- dimensional SiC MOSFETs," IEEE Electron Device Letters, vol. 40, no. 9, pp. 1382-1384, Sep. 2019, doi: 10.1109/LED.2019.2930712.

[15] G. C. Patil, S. C. Wagaj, and P. M. Ghate, "A simple analytical model of 4H-SiC MOSFET for high temperature circuit simulations," 2014 Annual IEEE India Conference (INDICON), 2014, pp. 1-5, doi: 10.1109/INDICON.2014.7030554.

[16] F. N. Abdul-kadir, Y. Hashim, M. N. Shakib, and F. H. Taha, "Electrical characterization of si nanowire GAA-TFET based on dimensions downscaling," International Journal of Electrical and Computer Engineering (IJECE), vol. 11, no. 1, pp. 780-787, 2021, doi: 10.11591/ijece.v11i1.pp780-787.

[17] Y. Hashim, "A new factor for fabrication technologies evaluation for silicon nanowire transistors," TELKOMNIKA Telecommunication, Computing, Electronics and Control, vol 18, no. 5, pp. 2597-2605, 2020, doi: 10.12928/telkomnika.v18i5.12121.

[18] F. N. A. Agha, Y. Hashim andd W. A. Abdullah, "Temperature characteristics of Gate all around nanowire channel Si-TFET," Journal of Physics: Conference Series, vol. 1755, 2021, pp. 1-7.

[19] Y. Yang, Y. Wang, S. Chen and T. Li, "Calibrate silicon nanowires field effect transistor sensor with its photoresponse," 2021 IEEE 16th International Conference on Nano/Micro Engineered and Molecular Systems (NEMS), 2021, pp. 676-679, doi: 10.1109/NEMS51815.2021.9451530.

[20] M. -S. Yeh et al., "Ge FinFET cmos inverters with improved channel surface roughness by using In-Situ ALD digital O3 treatment," in IEEE Journal of the Electron Devices Society, vol. 6, pp. 1227-1232, 2018, doi: 10.1109/JEDS.2018.2878929.

[21] H. M. Fahad, C. Hu and M. M. Hussain, "Simulation study of a 3-D device integrating FinFET and UTBFET," IEEE Transactions on Electron Devices, vol. 62, no. 1, pp. 83-87, Jan. 2015, doi: 10.1109/TED.2014.2372695.

[22] J. Alvarado et al., "SOI FinFET compact model for RF circuits simulation," 2013 IEEE 13th Topical Meeting on Silicon Monolithic Integrated Circuits in RF Systems (SiRF), pp. 87-89, 2013, doi: 10.1109/TED.2014.2372695.

[23] H. T. Al Ariqi, W. A. Jabbar, Y. Hashim, and H. Bin Manap, "Characterization of silicon nanowire transistor," TELKOMNIKA Telecommunication, Computing, Electronics and Control, vol. 17, no. 6, pp. 2860-2866, 2019, doi: 10.12928/telkomnika.v17i6.13084.

[24] S. Kim et al., "MuGFET," Nanohub, 2014, [Online]. Available: https://nanohub.org/resources/NANOFINFET.

[25] Y. Hashim, "Optimization of resistance load in 4T-static random-access memory cell based on silicon nanowire transistor," Journal of Nanoscience and Nanotechnology, vol. 18, no. 2, pp. 1199-1201, 2018, doi: 10.1166/jnn.2018.13956. 


\section{BIOGRAPHIES OF AUTHORS}
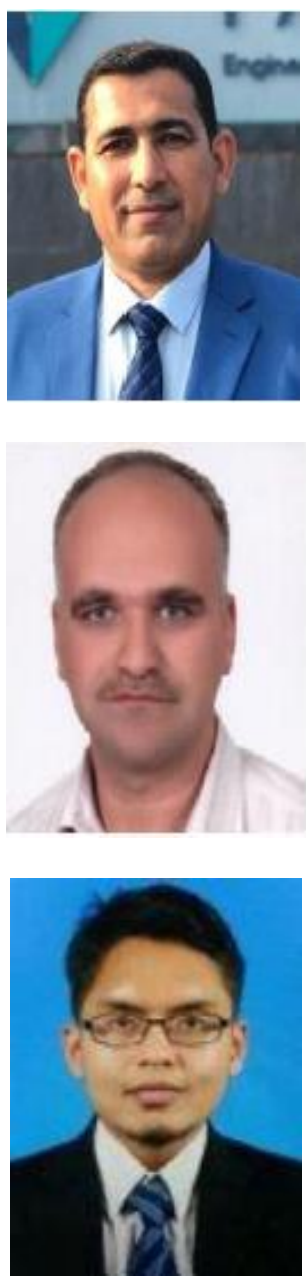

Yousif Atalla (D) 81 SC P the author was born in Iraq, he received the B.Sc. of Engineering in Electronics and Communications Engineering from Engineering Technical College, Iraq. He completed the M.Sc. in Electronics Engineering- Micro and Nano-electronics from Universiti Malaysia Pahang (UMP), Pahang, Malaysia. He is currently working as a Director of the Engineering Affairs Department-Salah Al-Din Governorate Council, Iraq. His research interests include Microelectronics and Nanoelectronic: FinFET transistor. He can be contacted at email: yousif.atalla81@yahoo.com.

Yasir Hashim (D) SC P the author was born at Iraq, 1969, he received the B.Sc. and Master of Engineering in Electronics and Communications Engineering from the University of Mosul, Mosul, Iraq, in 1991 and 1995, respectively. He completed the Ph.D. in Electronics Engineering- Micro and Nano-electronics from Universiti Science Malaysia (USM), Penang, Malaysia, in 2013. He is currently a Senior Lecturer in the Faculty of Engineering, Tishk International University, Erbil-Kurdistan, Iraq. His research interests include Microelectronics and nanoelectronics: Nanowire transistors, FinFET transistor, Multistage Logic Nanoinverters. The author has teaching experience in undergraduate fields of Electrical and Electronics Engineering for 17 years and supervised postgraduate student in Master and Ph.D. levels. He can be contacted at email: yasir.hashim@tiu.edu.iq; yasir.hashim@iee.org.

Abdul Nasir Abd Ghafar (iD SO SC P the author received the B.Sc. in Electrical and Electronics System Engineering, Master in Electronics System and $\mathrm{PhD}$ in Systems Engineering from Okayama University of Science, Japan in 2011, 2013 and 2016, respectively. $\mathrm{He}$ is currently a Senior Lecturer and Head of Program, Electrical Engineering Technology (Power and Machine), Faculty of Electrical and Electronics Engineering Technology, Universiti Malaysia Pahang (UMP), Malaysia. His research interest includes applied electronics, embedded system, optimization and simulation, robotics, and rehabilitation devices. The author has teaching experience in undergraduate fields of Electrical and Electronics Engineering for 5 years and supervised postgraduate students in both Master and PhD levels. He can be contacted at email: abdnasir@ump.edu.my. 